\title{
1 Generational tensions and solidarity within advanced welfare states
}

\author{
Asgeir Falch-Eriksen, Marianne Takle, and Britt \\ Slagsvold
}

\section{Introduction}

An advanced welfare state democracy is an institutionalized collective agreement on solving social problems and coordinating actions. Although welfare state democracies have different shapes, the scope of government is comprehensive, and citizens meet the welfare state services according to their needs and interests as customers, user groups, or clients (Goodin, 1988; Kumlin, 2002). An advanced welfare state penetrates its citizens' private realm and creates dependencies and expectations that "gives the state its paramount significance" across the social system it governs (Kaase \& Newton, 1995). Its paramount significance is a result of processes of democratic law-making, policy development, and budget-making, and leaves hallmarks such as welfare rights, universality, and solidarity. Through time, moulded by popular opinion and civic engagement, the welfare state has established an intrinsic connection to how citizens live their lives and how it secures each citizen's essential wellbeing and mitigate socio-economic hardships and health complications (Svallfors, 2012a).

According to Baldwin, a welfare state democracy as an innovation has brought about state systems that can carry "the possibility of solidarity" (1990). It alludes to a link between the solidarity of a social system on the one hand and a formal political-normative-embedded concept of solidarity enforced through a welfare state system on the other. Maintaining social solidarity within a functioning welfare state democracy can thereby be understood as the result of transferring mutual trust, a conception of legitimacy that carries collective support, and establish a type of moral obligation into the system of government itself, that is, establishing a type of political solidarity that draws upon the existing social solidarity between peers (Bayertz, 1999). Through democratic procedures of self-government, social solidarity is invested in the welfare state through time and across generations, where enduring political solidarity is necessary to secure a level of fundamental and universal wellbeing through different election cycles, political turmoil, crisis, and societal tensions (Banting \& Kymlicka, 2017).

This volume seeks to contribute to this problem-complex, namely, what lessons can be drawn from using a multifaceted concept of generation for generational analysis of the welfare state. By utilizing empirical data to study societal 


\section{Falch-Eriksen, Takle, and Slagsvold}

tensions between generations and towards the welfare state, we can elaborate on the type of solidarity that the welfare state carries; it depends upon and ultimately needs to persist across generations. It will, in particular, focus on critical challenges to solidarity confronting the welfare state, such as education, distributional justice, migration, education, and climate changes. The purpose is thereby to conduct generational analysis as a key to open up an understanding of how the welfare state develops, how tensions arise, how they are dealt with, or how they continuously are there to challenge the status quo of the welfare state. Our main goal is to understand tensions and solidarity between generations and between generations within advanced welfare states.

The importance of having a generational approach to the welfare state is more important today than ever. Following only the past decades, significant challenges have confronted welfare states across the world, as economic challenges leaving austerity measures and increasing costs, social and demographic developments with an ageing population and increased migration, rise in poverty levels after the financial crisis, and political developments such as a neoliberal agenda that is instilled to cut public spending, and the climate crisis and a deadly pandemic, are all examples of challenges that threaten the wellbeing of each individual within society, social solidarity itself, and the efficacy of welfare state.

With each following generation, challenges affect differently and pose a multitude of questions. For instance, will the welfare state be able to provide wellbeing for all? Will the rate of young manage to secure the welfare state as the relative amount of elderly increase? Will younger generations and future generations be left with covering the problems and costs of climate change? The challenges have sparked tensions within the social system regarding how different generations are affected by and respond to the challenges and how they become prioritized. Eventually, other large-scale challenges can cause changes in the composition of solidarity or the lack thereof. As tensions arise that can harm the welfare state, it becomes an ongoing task to keep political solidarity operative in the welfare state and aligned with social solidarity across generations.

\section{Generation as a multifaceted concept}

Karl Mannheim's seminal work on generations, "The Problem of Generations", published first in German in 1923, is still considered the canon for generational analysis. Although his outline is contested (See McCourt, 2012), it is still a fruitful point of departure for our attempt to raise conceptual clarity for how this volume will apply the concept of generation. In his conceptual discussions, Mannheim operates with several different concepts simultaneously. He began with the nutsand-bolts for such a concept. He argued that a generational concept could not by itself ignore the biological rhythm of birth cohorts: "sociological phenomenon of generations is ultimately based on the biological rhythm of birth and death" (Mannheim, 1952). However, although this is the point of departure, using such a positivistic approach to unveiling historical change and the potential of prediction of social change is both simplistic and fallible. Any potential for explaining social 
change had to develop the concept of generation from the biological rhythm but embed it in a sociological and a temporally spatially delimited space, something he referred to as the generation's "particular type of social location" (Mannheim, 1952). As Mannheim argued, the youth generation in Prussia at the beginning of the 19th century did not share the exact generational location as the youth generation in China (Mannheim, 1952). Although we can observe an emerging new "global generation" (Beck \& Beck-Gernsheim, 2009), and global events like COVID-19, challenge the idea of shared generational location analytically, partially dissolving contextual belonging and identity formation, generational location, and the heterogeneity it produces will continue to be a hallmark of social interaction and foundational for conducting generational analysis (Bristow, 2016).

Jane Pilcher (1994) correctly assumes that Mannheim's exposition of generation harbour many different generational concepts that each can lead to different types of analysis. Mannheim admits this himself as he argues the need for a differentiated concept that can maintain distinctions and provide clear-cut explanations (1952). Pilcher points out that generational location can internally stratify individuals into two main concepts of generation: social generation and kinship generation. While the former refers to the individual's insertion into the social and cultural currents of time, the latter refers to a geographical and cultural location. Furthermore, we will borrow from Bristow (2016), add a third concept dubbed historical and ascriptive generations. This type is about labelling what can be referred to as generational styles to describe certain key generational traits. The fourth is future generations, which increasingly has become a part of generational studies since the early 1970s (Tremmel, 2009).

\section{(1) Social generations}

Social generations refer to cohort-related phenomena, where individuals are born similar years and are age homogenous (Eisenstadt, 1971; Pilcher, 1994). This is what Mannheim refers to as the historical community of "actual generations". This means that the year you are born, you are also introduced to the world in line with all others born that year and inserted into what Mannheim refers to as the currents of social and cultural forces (Mannheim, 1952). Within each social generation, every member can influence and infuse the rest of the generation wittingly or not. Age and how it progresses reflexively with the social and cultural forces become a significant indicator for who you are as a historically embedded individual. Once your life is on the move through time, your life-course meets the larger sociopolitical environment together with all of your age cohorts. As Mannheim argued, the generational location relative to the historical time carries "certain feelings of behaviour, feeling and thought" (Mannheim, 1952).

However, since Mannheim wrote his essay a hundred years ago, society has changed, particularly with regard to mass democracies, rights, and advanced welfare states. On the one hand, the welfare state has become all-encompassing and intervenes in people's lives from birth to death. It has taken over many previously solved tasks in families, such as childcare and elderly care. This puts constraints 
on all generations, particularly young people who do not fill key positions in society and the state administration. The welfare state schemes have made young people less dependent on their parents, but they have become more exposed to the state bureaucracy's anonymous constraints (Elias, 2013).

On the other hand, the degree to which social integrations have brought citizens together in self-governing, that is, democratic, social communities have no historical counterpart. In democratic welfare states, the norm of civic engagement links each citizen to become architects of what needs and what interests the welfare state is set to meet (Goodin, 1988). Hence, an advanced welfare state democracy, where citizens enjoy rights and benefits, cannot assume there will always be passive members of different cohorts. As people move through time, as citizens within a welfare state democracy, they are not passive bystanders who, in a deterministic fashion, become conditioned by the welfare state but are actively engaged in social change. Each citizen can participate actively and reflexively in modernizing and shaping the welfare state to fit new needs in line with modern demands (Rothstein, 1998).

\section{(2) Kinship generations}

Kinship generations are depicting the membership in the same historical community and with "certain definite modes of behaviour, feeling and thought" (Mannheim, 1952). Kinship as a generational location is the immediate social context. It does not necessarily involve shared geographic location, but it denotes a social network tied together through thick relationships of trust, i.e. by familiarity (Luhmann, 2000). Generation becomes a matter of particularistic role-understanding, where a person understands who it is relative to age and position in the life cycle and what is expected of them from what generation they belong to within the immediate social context. Kinship generation is also hierarchical and asymmetrical, especially between parents and children and throughout the local community, where individuals carry distinct generational roles. This generation concept is often related to a biological perception of a generation because some type of descent is involved. The mother is in one generation, and the next one is her child. However, the key issue is how such role patterns work across generations as they are embedded as a social type in kinships.

Although every individual belongs to both a social generation and a kinship generation, the two generational concepts have different connections of belonging within the social system - one horizontal and intra-generational, and the other vertical and intergenerational. Whereas social generations are connected to the social roles and phenomena pertaining to birth cohorts, kinship generations have community belonging combined with thick trust relationships (Baier, 1986; Luhmann, 2000). Also, common to both concepts is that generations are reflexively reacting to and contribute to shaping societal circumstances as individuals age, but they do so differently. In social generations, each individual remains the same generation as time goes by, growing older. In kinship, they shift roles and identities across generations as they grow older, and they replace 
generations, and new expectations are bestowed upon them in new roles. The generational shifts can, for instance, be between child and youth, youth and young adult, young adult and parent, parent and grandparent, and so on. The length of each of these generations can vary through time (Krishnamoorthy, 1980).

As each individual simultaneously belongs to kinship and a social generation, it also tells us how generational norms and expectations shape the individuals, their identity, and how they are inserted and belong in a social system. As social generations go through life simultaneously, each generation unconsciously becomes a unit that can be expected to carry certain norms and that can have different challenges as time goes by. In contrast, each individual's kinship generation depicts personal roles and thick social bonds, and a sense of intergenerational solidarity.

\section{(3) Historical and ascriptive generations}

Historical and ascriptive generations are meant to capture those generation types that, for some reason, are labelled. Those providing such a label usually seek out conjoined birth cohorts labelled according to a particular historical period, depicting strong characteristics of the current time or social change. Locating and capturing generations that reflect cultural expressions, an identity or a conflict that has been a driving force of social change, a political mobilization, and so on has long been imperative to generational analysis (Bristow, 2016; Frith, 2005). To Mannheim, those within a social generation identifying with such a label not only belonged to the same generational unit but also belonged to the generational unit that realized its "potentialities" for social change or carried the cultural or social currents of the time. To Mannheim, a generational unit like this carried a new generational style that "creates new collective impulses and formative principles original to itself” (Mannheim, 1952).

In this volume, we will denote historical generations as generational styles that qualify the test of a generational self-definition (Bristow, 2016). This selfdefinition is anchored to distinct social generations reflective of a generational style embedded in social change or phenomena through historic time, "on the trigger action of the social and cultural process" (Mannheim, 1952). Ascriptive generation is also a label and depicts a widespread use of generational analysis. The ascriptive generations are rather brought together, not by the belonging to a social generation and a matter of social change or phenomenon but rather by accidental commonalities (Bristow, 2016).

Whereas historical generations can be illustrated through, e.g. the boomer generation and the digital generation, ascriptive generations, on the other hand, are more undefined and uncoupled from social generations, such as generation $\mathrm{Z}$ or Y or millennials or other dubious terms (Bristow, 2016). As will become clear later Chapter 10, the popular use of ascriptive generation has blurred the field of research-based generation analysis with its popular use. 


\section{(4) Future generations}

Future generations are defined as all generations that come after those living. The main reason for including this fourth concept is the realization that today's generations can affect the future more than ever before and in a great variety of ways. Most prominent is the increasing recognition of the finite nature of the planet's natural environment, including the atmosphere, the ozone layer, the global system cycles, the climate system, genetic and species diversity, etc. In parallel with recognizing the finite nature of the planet's natural environment, the concern for future generations has increasingly been included in legislation and policy, but also in generational studies (Tremmel 2009). Behind this attention is a common concern about highly problematic consequences if present generations transfer irreversible environmental damages to individuals born in the future. There is a broad global agreement that environmental resources need to be sustained for individuals born in the future. As such, the natural environment is increasingly understood as the world's shared heritage for both current and future generations.

This volume will utilize all the four concepts to conduct a generational analysis of the welfare state to answer many questions. How are tensions between generations challenging an advanced and robust welfare state? How are tensions or solidarity understood when the young and old generations face the common welfare state challenges differently? How can stability prevail as some generations define the politics and composure of a costly welfare state's polity and others have no voice or representation? The different contributors have explored different ways to study tensions and solidarity between generations within the welfare state by discussing such questions. Hence, this book seeks to unravel causes of change and motivations for change across time, unveil tensions that cause change and de-stabilization.

\section{Reaffirmation of solidarity in advanced welfare states}

The democratic and advanced welfare state is a legal-administrative type of government construct that can harbour a normative conception of justice containing mutual trust, democratic solidarity, and redistributive solidarity (Banting \& Kymlicka, 2017). The development of the advanced welfare state has gone in tandem with an increased division of labour and specialization. It has historically led welfare benefits to become a matter of welfare rights and public provision of, e.g., elder- and childcare, medical treatment, unemployment benefits, pensions, and education (Goodin, 1986). As they live their lives, citizens interact with everything from street-level bureaucracies in health care services to libraries, to public transport, as customers, users, and clients. Through budgets, letters of assignment, guidelines and routines, and street-level practices, the government is meant to seek out and meet its citizens' needs. The welfare state must also be understood as a response to a prevalent need for collective coordination and problem-solving, striving for a sense of justice, mutual trust, and solidarity (Habermas, 1996). 
Hence, an advanced welfare state can easily be referred to as the most complex expression of social coordination and problem-solving designed through history. Its complexity has further escalated through system differentiation, division of labour, development of new knowledge and technology, and steadily incorporating an ever-expanding pluralism on ways to live life (Giddens, 1990). Today, advanced welfare states include everything from public schools, health and social services, kindergartens, child welfare services, and even communication infrastructure - it is a complete and self-sustained system governed through democratic politics and public spending. Across Europe today, there is vast support for this type of state-construct (Meuleman et al., 2018).

Citizens being motivated towards, or acting in solidarity towards, the welfare state has maintained and enforced the welfare state throughout generations. Since maintaining a welfare state scheme has been on the agenda, efforts have been rather successful in overcoming past tensions and past conflicts. However, the welfare state is a product of each generation as they run their course throughout life. New generations have impacted the welfare state's design differently, but generations are also shaped by the societal norms they are embedded in. Hence, the welfare state has developed to fit the new needs of new citizens.

One of the most significant challenges for the general support and prevalence of the welfare state is that it is constituted by a stable set of rules, procedures, and decision-making, while the social system it governs is in constant flux. Each generation is constantly on the move, through time, and as their age preferences are altered and new generations are met by a welfare state designed to fit others' needs. In this way, for a democratic welfare state to maintain its underlying principles, it needs to reinvent itself to fit the changing needs and expectations of the fluctuating social system.

\section{Tensions in the advanced welfare states}

All living generations are affected simultaneously by social forces, cultural shifts, challenges, significant events, and crises. This creates tensions depending on different generational locations, as different generations carry different interests and needs that they might want a welfare state to contribute solving. Also, a welfare state is a stabilized set of norms through legislation and government procedures, which creates tensions towards the continuously moving interests and needs within the social system itself (Habermas, 1996). Typically, tensions would not involve a call for significant social change, escalate to a conflict, or leave demands for substantial shifts in welfare state programmes and policies, but predominantly constitute the steady flow of calls for social change that is an incremental adjustment of how social coordination and problems are solved through the parameters of the welfare state itself.

While Mannheim's work has laid the foundation for the sociology of generation and generational analysis, Norbert Elias's work has been in the background. There is, however, an overlap between their theoretical approaches. Like Mannheim, Elias saw generations as bound to biological factors, the birth and 
death of individuals, and how they were embedded into their social conditions and experiences through time. However, as John Connolly (2019) points out, Elias offers a more comprehensive theory to understand tensions and conflicts between generations. In his book Studies on the Germans (2013), he shows how tensions arise between generations through the opening or closing of channels for young people's opportunities, in terms of life opportunities, meaning, and upward mobility. He does not perceive access to key positions in society as a planned process in which the elderly open or close to the young, but an outcome of societal change in which wars, revolutions, economic development, and peace are central. Empirically, Elias studied how life chances were small for the young generations in the Weimar Republic in the 1920s and the 1960s and 1970s in Germany. A central issue for Elias is that the individualization process, secularization, and security from hunger lead the young generations to search for meaning and fulfilment in society. This means that the understanding of tensions between generations not only contests economic, social, and cultural resources but also goes beyond such basic concerns into the social roles of generations, how intergenerational tensions arise, and tensions towards how society is governed (Elias, 2013).

Lived lives, however, is continuous. Having past generations designing how the welfare state operates will lead to practical tensions between interests and reasonable claims upon resources among those who designed the welfare state and those who live by it. More substantively, new generations bring new norms of interaction or adjust old norms and carry reasonable expectations that perhaps do not fit well with what the current welfare scheme provides. Although young generations carry welfare rights that can grant them benefits, they might not be in a position to change them. To this volume, however, tensions are not necessarily bent on becoming conflicts. Tensions are everything, from the necessary societal friction between generations, between generations and the welfare state in the one end, to the threat of devastating systemic crisis due to conflicts in the other.

The necessary tensions can be located within the welfare state itself. For instance, how the welfare state's development is intimately connected to the social sciences and their ability to point out social discrepancies and recommend measures to solve new challenges and identify problems continuously unveil tensions between generations (Giddens, 1990; Wittrock \& Wagner, 2017). Over the years, solving collective problems and coordinating collective action has led to the dependency on professional discretionary decision-making to fit citizens' various needs and interests (Goodin, 1986; Lipsky, 2010). Addressing new needs and new interests across time has led to the development of complex bureaucracies involved in implementing legislation and policies that keep affirming and reaffirming the welfare state across time. Tensions between generations and the welfare state can be located at any joint in the welfare state complex.

Also, prior to any development of the welfare state itself or reflexively with the welfare state is the gradual increase of complexity of the social system itself and the character of each individual's life-course within it. For the past hundred years, each decade has been characterized by modernization processes that have increased social complexity (Giddens, 1990). The economy, science, politics, 
law, education, religion, and so on have become socially separated functional spheres that have continued to differentiate themselves into an increasing number of subsystems, and which all can be assumed could be the source of tensions. In sum, answering the needs and interests across such a vastly complex social system is what establishes an advanced welfare state.

\section{Generation perspective on the welfare state}

This book is divided into three parts, each anchoring the concept of generations in a different tradition. The chapters focus on tensions and solidarity between generations from varying perspectives and illuminate consequences for the welfare state. The first part focuses on the politics of generation and embeds the concept of generation in light of democratic governance, polity, and future generations. The second part focuses on generations within families through the challenges of migration, inheritance, and education to counter marginalization. In the third part of the book, two distinct generations are focused upon: the digital generation and the boomers. It also has a chapter on the popular use of generation analysis.

Most of the chapters draw on Norwegian data. The intention is to utilize Norway as an example of a stable and advanced welfare state. Each chapter aims to apply a generational concept or a combination of either social generation, kinship generation, historical generation, or future generation when analyzing the data. The chosen topics that inform the different applications of the concept of generations are relevant across nation-states attempting to maintain and enforce solidarity within the welfare state despite tensions that challenge or change it.

In the end, the book has a theoretical chapter about generations and how it is embedded in a social order that creates solidarity, which again becomes embedded in a legal form of the welfare state. In Chapter 11, Asgeir Falch-Eriksen discusses how and why the concept of generation must be able to explain how a social system designed to redistribute goods and services last across generations. The focus is on how social order carries mutual trust and solidarity sufficient to make the welfare state survive through the everyday run of the mill collective interaction and logrolling politics, to expedite regular problems efficiently and overcome crises and devastating challenges, and remain over time as a socially integrated whole, collectively coordinated. To explain the resilience of a welfare state, a concept of generation is sought that would explain social integration processes, which develops, affirms, and reaffirms a level of solidarity that is continuously operative within the welfare state across time and concurrent generations.

\section{The politics of generations}

Basic to the first part of the book is that the welfare state is a stable and formal expression of solidarity that is contested and transformed in line with democratic principles of self-rule into a stable political-legal concept. This procedure of stabilizing norms into legislation also embeds a particular normative composition of solidarity into the welfare state. Once stable, the social system itself develops 
further and creates new tensions between what is stable within the welfare state and the dynamic within the social system. How can we use the concept of generation to understand challenges in politics as a matter of distributive justice, as a cleavage in politics, and towards future generations?

In Chapter 2, Axel West Pedersen and Mi Ah Schoyen discuss different approaches to economic redistributions across generations. They explore the implication in the domain of pension- and family policies. As a point of departure, they use two approaches to redistribution among concurrent generations. The first holds that inequality in distribution among social generations can be justified as long as they maximize individual welfare from a lifetime perspective. The second is a strictly egalitarian theory that holds equality in distribution between different age groups at any given point in time. The chapter explores the policy implications of these two alternative approaches to redistribution and attempts to flesh out a compromising third option.

In Chapter 3, Ann-Helen Bay and Axel West Pedersen explore the hypothesis that population ageing will also increase welfare state redistribution conflicts between young and old. The basis is that the younger population will oppose a too heavy burden placed upon them by their older generations. Simultaneously, the elderly will use their increased share of the electorate to push their best interests through welfare state redistribution. With this hypothesis, the chapter investigates contemporary age orientation across a selection of European welfare states and voter preferences concerning policies that benefit the elderly and families with children, respectively. They find a tendency for a decline in spending bias in favour of the elderly across all countries. Their study also illuminates that voters generally support public responsibility for the wellbeing of the elderly and families. Their findings indicate a tendency towards convergence in age policies across Europe without clear signs of increasing conflicts between age groups.

In Chapter 4, Marianne Takle focuses on one of the most recent branches of generational analysis, namely future generations. The point of departure is the constitutional settlement that an increasing number of nation-states chose to accommodate, which stipulate the protection of future generations' access to a healthy natural environment. By so doing, the current generations are formally committed to holding the interests of future generations at heart while developing the welfare state further. This commitment can challenge the sustainability and design of the welfare state and lead to tensions between current generations' interests compared to future generations. The chapter moves one step further and elaborates theoretically on what solidarity towards future generations entails, which is different from what solidarity towards living generations holds. This theoretical concept's empirical relevance is evaluated by applying it to Norway as an example of a country that has included a protection clause for future generations in its constitution. 


\section{Generations within families}

The second part of the book is devoted to kinship generation and how challenges towards kinship generations can be understood through social generations. Individuals belong to a kinship generation, with their hierarchical structure and role expectations, but are also influenced by the societal norms belonging to their social generation. There is a long-standing tradition of studies of parent-child generational shifts and value transmission within sociology, focusing on intergenerational continuity (Kertzer, 1983).

In Chapter 5, Monica Five Aarset, Ingrid Smette, and Monika Grønli Rosten utilize lessons from Norbert Elias contributions to the sociology of generations to explore the challenges and dilemmas confronting descendants of immigrants as parents in welfare states. The chapter especially draws on the concept of assumed futures and how these become questioned by the so-called second generation when they become parents. In their qualitative interviews, they unveil ruptures in previously assumed futures and continuities in narratives on parenting and kinship roles. The parents' narratives illuminate how parenthood involves a renegotiation of their conception of belonging. The chapter shows how the concept of generation is linked not only to ideas of social change and continuity, but also to questions of belonging.

In Chapter 6, Hans Christian Sandlie and Lars Gulbrandsen address the interplay between the welfare state and family dependency, focusing on material transfers between generations through the example of housing. Their contribution explores whether or not public policy arrangements lead to a reliance between older and younger family members or if it enables autonomy. They explore how changes in housing policy and housing markets have led to different levels of intergenerational dependency within the family. They find that public policy arrangements shape the level of intergenerational solidarity. However, there is also a more ambiguous picture that is drawn compared to previous studies. Despite restrictions on mortgage-lending practices and an increase in house prices, they find no decline in the likelihood of entering homeownership among young adults. This is nevertheless not explained by increased parental support as parental support for housing has been stable.

In Chapter 7, Jon Ivar Elstad studies the educational expansion within the Norwegian welfare state. To a welfare state, the educational system's transformation has led to significantly improved educational opportunities for younger generations, which is widely held to be a ticket out of the poverty of past family generation. Furthermore, the educational expansions underpin economic growth and the development and maintenance of the modern welfare state. The chapter analyzes economic marginalization at age 35 in six successive birth cohorts born from the mid-1950s to the early 1980s. On average, the prevalence of marginal work income, disability pension, and social assistance remained largely stable from the earlier to the more recent birth cohorts. However, among those in the shrinking category of low educated, economic marginalization increased, resulting in wider educational inequalities between the low educated and other educational categories. Simultaneously, the economically marginalized composition 
changed, as the better educated constituted a steadily rising proportion of them. Such findings cast doubts that raising educational levels in the younger generations will, in themselves, be efficient policies for doing away with economic marginalization and reducing social inequalities through education.

\section{Historical and ascriptive generations}

The third part of the book focuses on three specific generations, frequently referred to in social change discussions today and often identified as distinct generations in Mannheim's sense. How can we discuss generation types, their social roles, and how they stand apart from other generations? We illustrate with two different generations that challenge the welfare state: the digital generations and the boomer generation, and discuss the popular use of ascriptive generations.

In Chapter 8, Idunn Seland and Christer Hyggen explore the young generation as the "digital generation". Although not yet settled, this generation clearly represents social change. Having an entire life with the internet and its possibilities makes this generation sharply distinct from earlier generations. The authors study the representation/discussion of the digital generation across more than 1100 Norwegian newspaper articles between 2010 and 2020. They seek out discursive trends in public discourse and the character of the dominant narratives on youth and digital media. Also, they add survey data on youth self-reported trends in the use of digital media aged 13-18 years. They find that the digital generation's portrayal shares traits with previous narratives on danger in youth culture and that there is a fear and a need to work against what the youth culture brings. However, the media narrative of young people's digitalized life is ambiguous, as their mastery is also met with admiration, excitement. They argue that the youth's personal experience has left them with an individualized responsibility in the digital domain, which puts this generation apart from previous generations.

In Chapter 9, Britt Slagsvold and Thomas Hansen present current images of the Baby boomer generation and explore these images' validity using survey data. During the last decades, boomers have more and more often been portrayed as a selfish, hedonistic, and demanding generation in the media. Being young and formed in the "wild 60'ies", their values and expectations of control are assumed to differ from the pre-war generation and the younger generation. The authors find that boomers represent a shift from past generations, as boomers have a considerably firmer belief in controlling their own lives and value hedonism significantly higher than the pre-war generation. Younger generations, however, do not represent a generational shift in this regard as their values and expectations are even more "boomer-like" than the boomers'. The blaming of boomers' character has gained momentum with increased worries about the future of the welfare state and climate crisis. The authors conclude that to blame the boomers for these problems instead of addressing the political and social causes behind the threats to the welfare state seems unwarranted and may create a mistaken conflict between generations. 
In Chapter 10, Ida Tolgensbakk explores the uses and abuses of Karl Mannheim's concept of social generation. As a point of departure, she examines the literature rooted in Karl Mannheim's concept of social generations. She traces Mannheim's influence through scholarly contributions to the popular media, which ascribe traits to conjoined social generations. Especially after 2000, and the eruption of internet media, ascriptive generations' use seems to have become more frequent, often creating in-groups and out-groups and becoming part of a popular categorization. The chapter explores how social generations seem to have transitioned from academic use, both in history and sociology, to become a part of popular culture usage and to depict certain key traits of conjoined social generations and set them apart from others. Furthermore, social generations have become theoretically disconnected from understanding social change and have become part of a simplistic media culture. Today this tendency has crossed back over to academia again, making much of the generation research simplistic and in conflict with the motivation of Mannheim.

\section{A new research agenda}

Across European countries, the welfare state still has broad support among popular opinion (Meuleman et al., 2018; Svallfors, 2012b). However, solidarity among citizens is not equally distributed towards all groups that are in need. For instance, solidarity towards unemployed and immigrants is weaker than for the elderly (Meuleman et al., 2018), reflecting an overall tendency of relatively high intergenerational solidarity in the Western-styled welfare states.

To Mannheim, the problem of generation was epistemic in character, and a generation approach was to be applied to explain social change, and often as historical discontinuities (Mannheim, 1952). Generation, Mannheim argued, was to be understood as one of the basic factors contributing to the "genesis of the dynamic of historical development" (Mannheim, 1952, p. 320). To explain social change, Mannheim wanted an approach that was between a purely positivistic approach, which focused on birth cohorts, on the one hand, and the romantic-metaphysical concept of generation on the other, which sought to unveil the "soul" of a generation (viz. "entelechies") (Kecskemeti, 1953). This book draws on a similar motivation but is not in and preoccupied with historical discontinuities that mark significant societal shifts. Hence, generation is not studied to explain significant social change and generational styles alone but to provide meaningful analysis of how the welfare state affects generations through the prism of a multifaceted generational concept.

By approaching the welfare state through generational analysis, we study continuity and change of society through the analytical level of the generation that is neither representative of the entire social system nor reducible to the individual personal level. Hence, studying generations provides insights into a core building block of sociology, the birth of persons, and how they are introduced and embedded in society through time, how they reflexively shape society and become shaped by society, and how they pass and exit society. Society would never be the same without generations quo generations. 


\section{References}

Baier, A. C. (1986). Trust and antitrust. Ethics, 96(2), 231-260.

Baldwin, P. (1990). The politics of social solidarity: Class bases of the European welfare state, 1875-1975. Cambridge University Press.

Banting, K., \& Kymlicka, W. (2017). The strains of commitment: The political sources of solidarity in diverse societies. Oxford University Press.

Bayertz, K. (1999). Four uses of "solidarity". In Solidarity (pp. 3-28). Springer.

Beck, U., \& Beck-Gernsheim, E. (2009). Global generations and the trap of methodological nationalism for a cosmopolitan turn in the sociology of youth and generation. European Sociological Review, 25(1), 25-36.

Bristow, J. (2016). The sociology of generations: New directions and challenges. Springer.

Connolly, J. (2019). Generational conflict and the sociology of generations: Mannheim and Elias reconsidered. Theory, Culture \& Society, 36(7-8), 153-172.

Eisenstadt, S. N. (1971). From generation to generation: Age groups and social structure. Transaction Publishers.

Elias, N. (2013). Studies on the Germans: Power struggles and the development of Habitus in the nineteenth and twentieth centuries. University College Dublin Press.

Frith, S. (2005). Generation. In T. Bennett, L. Grossberg, \& M. Morris (Eds.), New keywords: A revised vocabulary of culture and society. Oxford: Wiley-Blackwell.

Giddens, A. (1990). The consequences of modernity. Polity Press.

Goodin, R. (1988). Reasons for welfare: The political theory of the welfare state. Princeton University Press.

Goodin, R. E. (1986). Welfare, rights and discretion. Oxford Journal of Legal Studies, 6(2), 232-261. https://doi.org/10.1093/ojls/6.2.232

Habermas, J. (1996). Between facts and norms.contributions to a discourse theory of law and democracy (W. Rehg, Trans.). The MIT Press. http://website-pace.net/documents /19855/4491159/20180427-socdoc11 rev-interet-superieur-enfant-EN.pdf

Kaase, M., \& Newton, K. (1995). Beliefs in government (Vol. 5). OUP Oxford.

Kecskemeti, P. (1953). Introduction to Karl Mannheim. Essays on the sociology and social psychology, 1-11.

Kertzer, D. I. (1983). Generation as a sociological problem. Annual Review of Sociology, 9(1), 125-149.

Krishnamoorthy, S. (1980). A note on the length of generation. Genus, 167-171.

Kumlin, S. (2002). Institutions - experiences-preferences: How welfare state design affects political trust and ideology. In Restructuring the welfare state: Political institutions and policy change (pp. 20-50). Springer.

Lipsky, M. (2010). Street-level bureaucracy: Dilemmas of the individual in public service. Russell Sage Foundation.

Luhmann, N. (2000). Familiarity, confidence, trust: Problems and alternatives. In D. Gambetta (Ed.), Trust: Making and breaking cooperative relations. Department of Sociology, University of Oxford.

Mannheim, K. (1952). Essays on the sociology of knowledge. Routledge and Kegan Paul Ltd.

McCourt, D. M. (2012). The "problem of generations" revisited: Karl Mannheim and the sociology of knowledge in international relations. In B. J. Steele \& J. M. Acuff (Eds.), Theory and application of the "generation" in international relations and politics (pp. 47-70). Palgrave Macmillan US. https://doi.org/10.1057/9781137011565_3 
Meuleman, B., van Oorschot, W., Gugushvili, D., Baute, S., Delespaul, S., Laenen, T., Roosma, F., \& Rossetti, F. (2018). The past, present and future of European welfare attitudes: Topline results from round 8 of the European Social Survey. ESS Topline Series. https://www.europeansocialsurvey.org/docs/findings/ESS8_toplines_issue_8 welfare.pdf

Pilcher, J. (1994). Mannheim's sociology of generations: An undervalued legacy. British Journal of Sociology, 45(3), 481-495.

Rothstein, B. (1998). Just institutions matter. The moral and political logic of the universal welfare state. Cambridge University Press.

Svallfors, S. (2012a). Contested welfare states: Welfare attitudes in Europe and beyond. Stanford University Press.

Svallfors, S. (2012b). Welfare attitudes in Europe: Topline results from round 4 of the European social survey.

Tremmel, J. C. (2009). A theory of intergenerational justice. Routledge.

Wittrock, B., \& Wagner, P. (2017). States, social knowledge, and the origins of modern social policies. In R. Dietrich \& S. Theda (Eds.), 3. Social science and the building of the early welfare state: Toward a comparison of statist and non-statist western societies (pp. 90-114). Princeton University Press. https://doi.org/doi:10.1515/9781400887408 -005 . 
$\because$ Taylor \& Francis

Taylor \& Francis Group

http://taylorandfrancis.com 